University Ownership and Information about the Entrepreneurial Opportunity in Commercialisation: A Systematic Review and Realist Synthesis of the Literature

Christos Kalantaridis* \& Merle Küttim**

Journal of Technology Transfer

September 2019

(draft 2)

* London Metropolitan University, London, UK, e-mail: c.kalantaridis@londonmet.ac.uk

** Tallinn University of Technology, Estonia 


\title{
University Ownership and Information about the Entrepreneurial Opportunity in Commercialisation: A Systematic Review and Realist Synthesis of the Literature
}

\begin{abstract}
It is now increasingly acknowledged that universities, despite their research capabilities and ownership of the new technical information they generate, are able to transform only a small minority of the patents they hold into innovations. In the transition from research outcome to innovation, information about the entrepreneurial opportunity is important because the outcomes of academic research are distant from the marketplace: as they have not been conceived with consideration of practical use but solely in a quest for understanding a scientific phenomenon. This underpins the rationale for our study into the information conditions regarding the entrepreneurial opportunity in the context of the prevailing property rights regime. In addressing this issue we adopt a theory-led realist synthesis approach to the conduct of a systematic literature review. Whilst we find empirical evidence supporting the conclusions of theoretical models, i.e. the strengthening role of technology transfer offices, we also point to their shortcomings. We go on to argue that significant gaps in our knowledge, and thus our ability to act, remain. In response, we advance an agenda for future research that focuses on the exploration of alternative policy actions (interventions) that draw from different paradigmatic lenses and methodological approaches.
\end{abstract}

Keywords: commercialisation, university, information, entrepreneurial opportunity, property rights.

JEL Codes: O32, O34, D80, L26

\section{INTRODUCTION}

Going back to the 1980 s a new consensus emerged within policy and research communities: namely that publicly funded research at universities can stimulate innovation and economic growth (for a review see Mowery et al, 2004). This, in turn, led to a radical review of the role of universities in society and prompted the introduction of a set of policy reforms aimed at facilitating the exploitation of the research outcomes generated by academics. Foremost amongst these was the Bayh-Dole Act (variants of which were subsequently adopted across most developed countries) that conferred to universities ownership of the outcomes of academic research, replacing legislation that i) made them widely available to the public through dedication to the public domain (more recently revived in the form of commons type of solutions) or ii) inventor ownership. Both of these were viewed as sub-optimal, arguably, 
resulting in the under-exploitation of large numbers of patents on account of insecurity regarding their ownership (Mowery et al. 2004). The new arrangements were believed to provide the appropriate incentive structure for universities to 'harvest' research outcomes produced by academics, invest in commercialisation, and act as engines of innovative activity (Colyvas et al. 2002; Siegel et al. 2003).

Inherently positivist theoretical models developed in the mid-2000s, discussed in more detail in the following Section, provided an ex-post justification for the new property rights regime. These contend that the attainment of a critical mass of protected research outcomes is important in allowing universities to bear the cost of accessing information about the entrepreneurial opportunity and to invest in acquiring the expertise, embodied in technology transfer officers (hereafter TTOs), needed for commercialisation (Hoppe and Ozdenoren 2005; Hellmann 2005). However, to date research revolving around information regarding the entrepreneurial opportunity has remained in the shadows. This is because the commercialisation of university IP is viewed fundamentally as a challenge of mobilising new technical information (the term is used interchangeably with that of the research outcome) produced through academic research (Baldini 2009; Wu et al. 2015; Halilem et al. 2017; Kalantaridis 2019).

We believe that there is merit in bringing the disparate body of research on information regarding the entrepreneurial opportunity together through the conduct of systematic review of the literature as a new wave of scepticism about the effectiveness of the now dominant property rights regime emerges. This is because, despite considerable success in mobilising research outcomes - manifested in a profound growth in the number of disclosures and patents granted (Siegel et al. 2007; Lemley 2008; Siegel and Wright 2015), returns to 
university commercialisation, viewed here as a proxy for the value of the innovations introduced, remain modest (Abrams et al. 2009; Swamidass and Vulasa 2009; Valdivia 2013). Thus, 'only about 5\% of patents are licensed at most universities ... [t]he rest are a drain on office resources ... because of required maintenance and legal fees' (Ledford 2013, 472). This constitutes a potentially sub-optimal situation, one of under-exploitation of patents that impact adversely on economic growth, not greatly dissimilar to that that prompted the introduction of reform in property rights through the Bayh-Dole Act. It also relates to current debates about the evolving contribution of universities, the recipients of public funding for the purposes of research, in society (Maassen et al. 2019).

In this context, our paper sets out to address the question: what are the information conditions regarding the entrepreneurial opportunity and how does the prevailing property rights regime influence these? In addressing this question we will adopt a realist philosophy to a systematic review of the existing body of literature (Pawson et al. 2005). We use a theory-led framework based on a Context-Intervention-Mechanism-Output (CIMO) architecture (Denyer and Tranfield 2009) - to guide our analysis. This states that in a given context (C), i.e. the surrounding factors, both external and internal, and the characteristics of actors, the use of a certain intervention (I) - any action undertaken to achieve the desired outcome, invokes a generative mechanism $(\mathrm{M})$, and delivers the intended outcome $(\mathrm{O})$ (Denyer et al. 2008; Holloway et al. 2016).

Our framework combines insights coming from entrepreneurial studies, a disciplinary context that to date has failed to influence research on university commercialisation, with theoretical models from our empirical context. Specifically, we use the concept of opportunity discovery and the model developed by Hellmann (2005) to conceptualise information conditions of 
ambiguity: referring to instances where markets (for the invention) exist when decisions are made, thus, information can, but may not, be known by actors (Figure 1). The fundamental challenge confronting the actors revolves around their ability to access and process this information. This is distinct from opportunity creation, which together with the work of Hoppe and Ozdenoren (2005) help us trace conditions of uncertainty: i.e. instances where markets (for the invention) have yet to be formed when decisions are made so information is not only not known but also not knowable. Thus, actors must possess experience of taking decisions in such conditions, and engage in trial and error experimentation.

\section{Figure 1. Concept Map of the Paper}

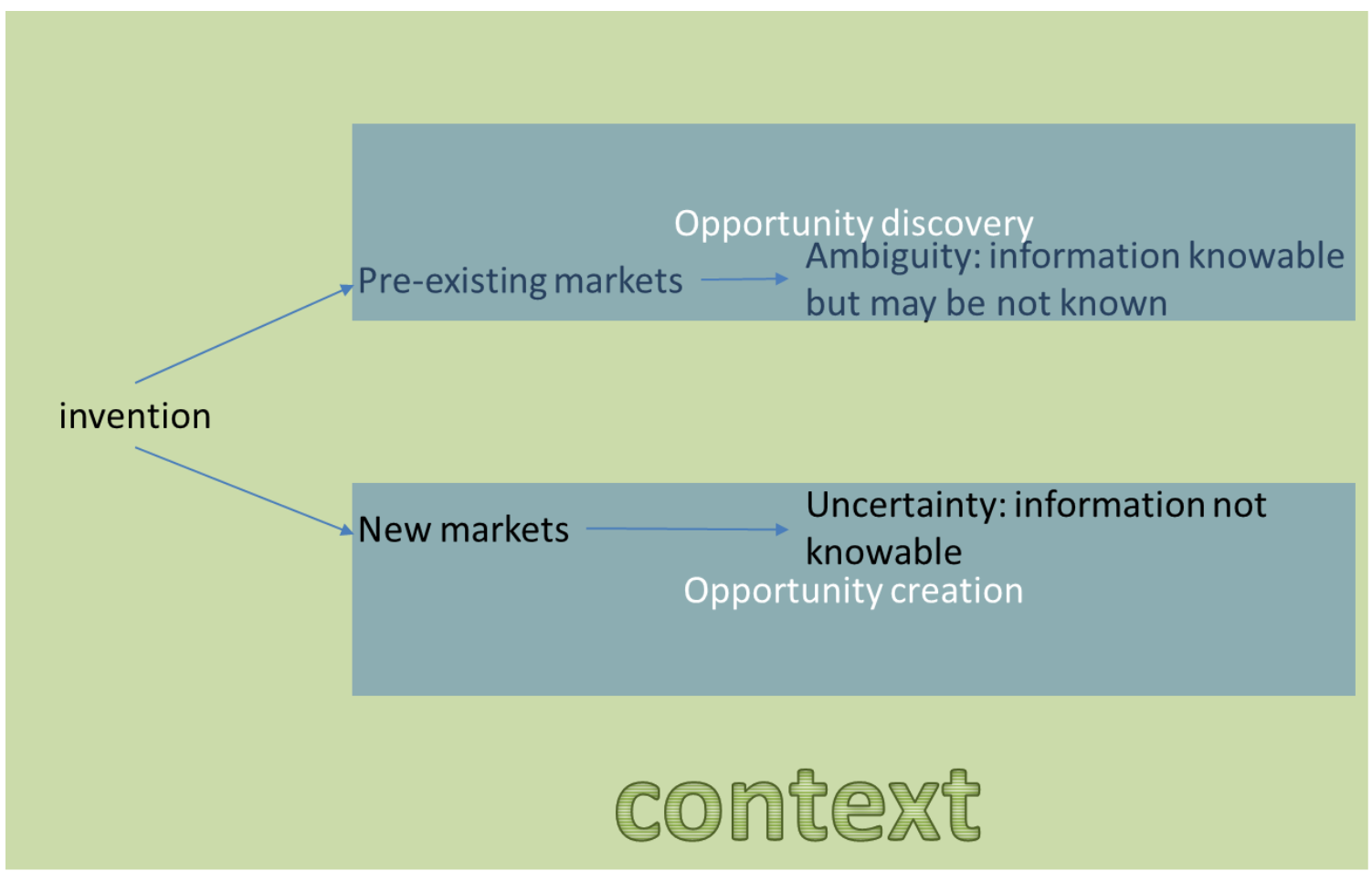

We believe that our paper contributes to the existing body of knowledge in three interconnected ways. Firstly, we initiate a process of reconceptualising the commercialisation of university IP in terms of the entrepreneurial opportunity rather than the research outcome. Secondly, we explore the implications of the pursuit of entrepreneurial opportunities for the 
expertise needed for its realisation and the effective commercialisation of university IP. Specifically, we identify actor expertise needed in taking decisions in information conditions of ambiguity and uncertainty. Lastly, we advocate radical, in the context of the literature reviewed here, reconsideration of the intervention (policy action) used in order to overcome the modest degree of transformation of university research outcomes to innovation. This goes beyond the effective (or not) implementation of what exists to the appropriateness of the prevailing property rights regimes and the identification of entrepreneurial actors.

The structure of our paper is as follows. The next Section unfolds theoretical constructs. Then the methodology used in collecting and processing published research is presented. The results of this exercise are presented in two Sections: one containing the findings of bibliometric analysis, whilst the second (and more substantive) content analysis. Then we proceed to discuss the results in the context of the research questions posed, and advance an agenda for future research. Finally, we offer some conclusions.

\section{THEORETICAL CONTEXT}

\subsection{Entrepreneurial Opportunity and Information Conditions Defined}

As stated previously research on, and policy action directed at the commercialisation of university IP focused heavily on how best to mobilise research outcomes produced through academic research at the expense of considerations revolving around the entrepreneurial opportunity. The latter concept comes from the field of entrepreneurial studies and, as is often the case in the social sciences, is defined in different ways by scholars (for a review see Davidsson 2015). Whilst we acknowledge this diversity we concur with Alvarez et al. (2013) that fundamentally entrepreneurial 'opportunity exists when competitive imperfections exist in product or factor markets' (ibid. 302). The exploitation of these opportunities in the pursuit 
of wealth lies at the core of, and defines, the entrepreneurial function ${ }^{1}$. Our definition of the entrepreneurial opportunity affords scope for diversity as to how these competitive imperfections are formed: a salient point both theoretically and in the empirical context examined here.

Theoretically, in the field of entrepreneurial studies, one prominent view understands opportunities as formed by exogenous shocks due to technological, political and social changes to pre-existing markets or industries that are discovered by entrepreneurs (Shane 2003). In this intellectual setting (hereafter identified with the concept of discovery), entrepreneurial opportunities exist objectively and independently of actor perceptions (Kirzner, 1973), and failure to recognise these is on account of the differential ability of actors to identify and exploit them as the information about these opportunities may be dispersed (Hayek, 1945). A different perspective contents that opportunities are formed endogenously by the entrepreneurs who created them (Alvarez and Barney 2007). Thus, opportunity creation foresees opportunities as largely unrelated to current markets and industries, whereas their exploitation depends on the actors' prior beliefs, together with their understanding of the resources and abilities (Sarasvathy, 2001).

Information conditions in the former case are defined by the availability of objective information that can be accessed and used by entrepreneurs in the process of exploiting opportunities. Thus entrepreneurial actors may seek and access consumer information acquired through interactions with previous customers or from evaluations of products and

\footnotetext{
${ }^{1}$ This constitutes a wide definition of entrepreneurship that encompasses but goes beyond Kirzner's (1973) important contribution that identifies entrepreneurs with awareness (alertness) to opportunities to which other actors may not be aware. Breadth is important in order to accommodate research not only on opportunity discovery (the focus of Kirzner) but also opportunity creation.
} 
the willingness of users to pay for them, as well as information about competitors (Hoeffer 2003). In the latter context, entrepreneurs rarely have information about alternative outcomes and the probability of achieving these outcomes. Thus, historic data and information from previous efforts may make actors resistant to new ways of doing things producing negative outcomes (Levitt and March 1988). Instead, in these information conditions the ability to 'coenact with others in order to influence their social constructions ... actors who may have already gone through this process may not be concerned with the uncertainty of outcomes, or the trial-and-error decision making process through experimentation' (Alvarez et al. 2013, 309-310) matters most. It is worth acknowledging here that there have been recent criticisms of paradigmatic inconsistences in the distinction between opportunity discovery and opportunity creation (Kitching and Rouse 2017) - though their consideration go beyond the scope of our inquiry.

\subsection{From Entrepreneurial Opportunity to Commercialisation Models}

In our empirical context the distinction between opportunity discovery and opportunity creation is reflected in theoretical modelling ${ }^{2}$ of information conditions. Those revolving around discovery are articulated by Hellmann (2005), who focuses on the problem of '[s]cientists [who] often do not know what the potential uses of their scientific discoveries are, nor do they know what firms may be potentially interested... [and] firms [that] are often unaware of what scientific discoveries may be valuable for them' (ibid. 625). In this context, also examined by Macho-Stadler et al. (2007), information about research outcomes and firms' innovative needs pre-exists, and can be objectively accessed, albeit at a cost, by actors.

\footnotetext{
2 The focus on these models is partly because they address the problem examined in our paper and partly due to their influence. Indeed, they are referred to by around a third of the papers reviewed here and published post-2005 (i.e. when the first of these constructs was published).
} 
This information condition bears some resemblance with Burt's (2004) notion of a structural hole, i.e. an "empty space" in the flow of information between two groups of actors (scientists and firms) that do not otherwise interact. Actors on either side of the structural hole have access to different elements information however, this does not flow between them. Thus, the matching process, or the bridging of the structural hole, by which scientists and firms find each other is central for commercialisation. To find a match, for Hellmann (2005), who adopts the point of view of the knowledge producer, a scientist must invest in search activities, whilst remaining focused on her core activities: scientific research. This model contents that patent protection enables the scientist to delegate all search activities to the technology transfer office. The office is viewed as having a lower cost of search because of specialisation and/or because of a lower opportunity cost of time, as it can employ individuals (officers) who specialise in the matching task. In a manner reminiscent of Burt's (2000) broker it bridges the structural hole realising the opportunity involved in establishing information flows between two groups (scientists and firms).

Central in opportunity creation in the context of university commercialisation, according to Hoppe and Ozdenoren (2005), is dealing with uncertainty about the profitability of technical information and specifically the assessment of its commercial value particularly in instances that may lead to entirely new products without knowing the demand for these. In this setting, actors, and particularly firms, rarely have information to evaluate the alternative outcomes associated with their decisions and the probability of these different outcomes being realised (Knight 1921). Thus, the fundamental challenge for firms is that of observing the quality level of an invention before they make the decision to invest (Hoppe and Ozdenoren, 2005). However, this involves costs around the acquisition of expertise to identify profitable ones from unprofitable ones. These costs may deter firms from investing in innovation even when 
positive gains could be realised. This opens up the scope for intermediary agents ${ }^{4}$ : who could achieve economies on the cost of expertise needed in order to differentiate potentially profitable from potentially unprofitable inventions. The intermediary as an individual may invest in human capital development that would facilitate the identification of profitable inventions, whilst at the organisational level (e.g. a university) the development of this function revolves around the cost of hiring individual who possess this human capital. Hoppe and Ozdenoren (2005) go on to suggest that intermediary incurred costs can be recovered if the IP pool is large enough to achieve economies of sharing expertise. They claim that there exists a threshold for the number of inventions above which expected payments are, in aggregate, sufficiently large to cover the costs of expertise investment.

Both models converge to the same intervention: intermediation. This is necessitated because the costs of intermediation, which, if incurred by the scientist or the firm, may act as an obstacle to the commercialisation of university IP. However, they diverge on the origin for these costs. In the case of Hellmann this involves the acquisition of the (knowable in preexisting markets) information needed in order to perform a matching function and the development of the expertise needed in order to process this information and perform the matching function. In contrast for Hoppe and Ozdenoren intermediaries need to invest in the expertise needed in order to evaluate the relative profitability level of different inventions in conditions where information is not knowable.

\footnotetext{
${ }^{4}$ The intermediary is an actor, individual or organisation, that assumes the role of facilitation or mediation between the parties in order to contribute to the relational context and to the development of the process of commercialisation (Battistella et al. 2016) and decrease search costs for other actors (for a review of relevant arguments please see Kirchberger and Pohl 2016).
} 
A necessary condition for the emergence of TTOs, is university ownership of research outcomes generated by scientists. Undoubtedly the most detailed exposition comes from Hellmann (2005) who, whilst he acknowledges that patents may dampen the incentives of firms to pull discoveries out of academia, concludes that they (patents) are important in bolstering scientists to push their research outcomes to industry. Any negative effects on enterprises may be mitigated on account of the ease of bridging the science market gap where the role of TTOs is critical. For Hoppe and Ozdenoren (2005) university IP is an essential pre-condition for TTOs to be able to perform their intermediating role.

The implications of differentiation, both sectoral and disciplinary, remain unexplored by both models. Hellmann (2005), who approaches the problem from the point of view of the knowledge producer, remains unaware of the effects of sector that are particularly profound for firms. Moreover, he narrows the scope of his investigation solely upon research that is applied in nature and has a single use, as he considers basic research, which may have more than one uses, as unpatentable. Hoppe and Ozdenoren (2005) whilst acknowledging that 'one TTO may specialize in biotechnology, whereas another one may specialize in communication technology' (ibid. 497) fail to explore how the specificities of different sectors may effect commercialisation outcomes. However, arguments advanced elsewhere in the literature show that sectoral and disciplinary differences are important, particularly as they define the distance between university IP and the marketplace. Specifically, in sectors such as biotechnology and materials with mainly analytical knowledge base, probably because they are characterised by proximity to scientific principles, research outcomes are horizontal in nature: in the sense that they can be used across a wide set of applications in different industries (OECD 2009). Thus, these outcomes originating from academic research tend to be generic in nature, creating a broad range of entrepreneurial opportunities: '[t]his can be a 
source of competitiveness in a fast changing context, but it also requires major decisions regarding the actual application(s) to be pursued' (Salavisa et al. 2012: 382) and may lead to radical innovation (Asheim and Coenen 2005). Their application, in turn, requires information that may not be available (such as how will consumers respond to the introduction of a radically new product) when decisions are made: aligning more closely with the challenge identified by Hoppe and Ozdenoren (2005). It also means the challenge TTOs face in the commercialisation process is generating interest for and further investments into technologies that may have potential, but are too immature to be assessed by venture capital for their commercial possibilities (Valentin and Jensen 2007). This differs significantly from sectors such as software and engineering with mainly synthetic knowledge base where advances can be described as mostly incremental in nature due to the application or novel combination of existing knowledge (Asheim and Gertler 2005). Thus, even though they take place at a very rapid pace this occurs in a narrower scope of entrepreneurial opportunities (Salavisa et al. 2012). This in turn aligns more closely with the challenge identified by Hellmann (2005), where information is pre-existing and can be objectively obtained at a cost.

The equilibrating nature of the models examined here mean that they fail to capture the constraining or enabling implications of decisions made in one point of time for decisions that will be made in subsequent time periods: i.e. path dependence. This is particularly the case both at the sectoral and the organisational level. Regarding the former, for example in biotechnology and materials, where the challenges imposed by uncertainty are particularly profound, decisions taken at one point in time determine the direction of future research and commercialisation for the specific actor concerned. An empirical illustration of this comes from the case of graphene. Chen et al. (2013) identify through bibliometric analysis the main research teams leading publication on i) graphene preparation, ii) applications and iii) laser 
applications. They argue that the decision to pursue one specific line of invention influences the scope for future research and invention activity in a specific research team. Once a patent is awarded, enterprises or other potential users may approach the university with the aim of obtaining the legal right to use the invention for a particular purpose. At this point information becomes knowledge as it is internalised by a 'knower-user' and shaped, using perceptions and experience, into a commercial venture (innovation). Another example, involving synthetic knowledge, revolves around Penn State's development of heart-assist devices (Feller and Feldman, 2010). This illustrates the effects of path dependence at the organisational level, i.e. how decisions taken in one point in time by an organisation (university or firm) will determine its experience with information search and its ability to identify and assimilate new information in the future (Vega-Jurado et al. 2008). Specifically, how past decision of firms collaborating in the transition from invention to innovation (e.g. Thoratec Corporation, 3-M and Abiomed), shaped the process. In particular it points at absorptive capacity as a path dependent dynamic capability, regarding information the acquisition, assimilation, transformation and exploitation of information accessing, which enhances an organisation's ability to gain and sustain competitive advantage (Zahra and George, 2002).

\section{METHODOLOGY}

The study adopts a theory-led realist synthesis approach to the conduct of a systematic literature review. Realist synthesis enables us to review the literature on complex social systems, and affords us a theory-driven approach to the evaluation of published work as it identifies the underlying factors that characterise problems and influence the outcome of interventions (Pawson et al. 2005). Thus, it encompasses three stages: i) the identification/creation of an initial theoretical construct/framework, ii) the conduct of the 
literature search, and iii) refining the theoretical constructs/framework taking into account the research results obtained in the papers reviewed (Ellwood et al. 2017).

\subsection{The Analytical Framework and Research Questions}

In this Section we draw together the different threads of the earlier discussion in order to construct an analytical framework and develop a set of questions that will guide our literature review. The analytical framework is structured according to the 'CIMO logic' (as described in the Introductory Section of the paper). Our starting point is the identification of two generalisable contexts reflecting information conditions linked with entrepreneurial discovery and creation (described in a previous Section) captured with the terms of ambiguity and uncertainty respectively. The former condition relates to information that is relevant, and could be known but may not be by participants because of search costs or information processing capabilities. The 'knowability' of information suggests that markets for these inventions may be pre-existing. In the latter situation information is relevant but not knowable as participants are aiming to influence future states of affairs, markets that may not exist at the time of making decisions, and speculate the response of other actors (competitors, suppliers, and customers) (Kalantaridis 2019). There are a number of other (than pre-existing markets) key influences, namely sector and discipline and path dependence, identified in the theoretical modelling discussed in the previous two sub-Sections, shaping these information conditions. The intervention advanced by theoretical models in both of these contexts is the same: the intermediating TTO at the centre of an abstract relationship involving producers of knowledge (academics) and users (firms) (as highlighted in Figure 2 below). The mechanism that underpins this intervention is the conferment of ownership rights upon the research outcomes produced by academics to universities. The envisaged/desired outcome, by theoretical constructs, is the commercialisation of the research outcome. Lastly, we develop 
three research questions, cutting across contexts. These questions have been used as a means of organising the content analysis, and constitutes the focus of the relevant sub-Sections (5.1, 5.2 and 5.3).

Figure 2: The Analytical Framework and Research Questions



\subsection{The Conduct of the Literature Search}

In the context of this theory-led approach, the systematic literature review (ii) has gone through several carefully devised steps ${ }^{5}$, including planning the review, conducting it,

\footnotetext{
${ }^{5}$ This allows the researchers to reduce their bias towards favourable studies and to define beforehand and make transparent the actions (steps) undertaken for gathering the literature sources (White and Schmidt 2005).
} 
reporting, and disseminating the results (Tranfield et al. 2003). Our search focused on two databases: Scopus and Web of Science. These databases were selected for their very broad coverage of high-quality research. The keywords used were "commercialisation" (also with its US spelling) AND “university" AND “property rights”, generating a list of 257 papers. In order to select only papers addressing the topic of the study, a set of inclusion and exclusion criteria of papers were defined and implemented across three steps (presented in Table 1 below): the aim being that these provided an unbiased basis to decide upon which articles to focus the review (Tranfield et al. 2003; White and Schmidt 2005). Each of these steps was performed independently by each of the authors: whilst differences were reconciled at the end of each step.

Table 1. Inclusion and exclusion criteria for literature search.

\begin{tabular}{|c|c|c|c|}
\hline & Stage & Criteria & $\begin{array}{l}\text { No of } \\
\text { studies }\end{array}$ \\
\hline 0 & $\begin{array}{l}\text { Bibliographic } \\
\text { searches }\end{array}$ & Original 'long list' of papers & 257 \\
\hline 1 & $\begin{array}{l}\text { Reading of } \\
\text { titles }\end{array}$ & $\begin{array}{l}\text { Inclusion criteria: } \\
\text { 1) the studies addressed university-industry knowledge and } \\
\text { technology transfer, including commercialisation. } \\
\text { Exclusion criteria: } \\
\text { 1) the studies focused on the development of specific technology } \\
\text { without discussing how it was transferred to the market; } \\
\text { 2) the studies addressed mainly the university's contribution to } \\
\text { regional and economic development. }\end{array}$ & 170 \\
\hline 2 & $\begin{array}{l}\text { Reading of } \\
\text { abstracts }\end{array}$ & $\begin{array}{l}\text { Inclusion criteria: } \\
\text { 1) the studies explored the stages and characteristics of university- } \\
\text { industry commercialisation process as a central issue, e.g. through } \\
\text { the functioning of university TTO; } \\
\text { 2) the studies addressed the commercialisation IP developed and } \\
\text { protected legally by the university; } \\
\text { Exclusion criteria: } \\
\text { 1) the studies compared mainly different commercialisation routes, } \\
\text { e.g. licensing and spin-offs; } \\
\text { 2) the studies discussed mainly the ethical considerations of } \\
\text { commercialisation like patenting limiting access to public } \\
\text { knowledge; } \\
\text { 3) the studies addressed the commercialisation of IP developed by } \\
\text { enterprises. }\end{array}$ & 59 \\
\hline 3 & $\begin{array}{l}\text { Reading of } \\
\text { full texts }\end{array}$ & Inclusion criteria: & 25 \\
\hline
\end{tabular}




\begin{tabular}{|l|l|l|l|}
\hline \multicolumn{1}{|l}{} & $\begin{array}{l}\text { 1) factors influencing university-industry commercialisation process } \\
\text { were analysed in a detailed way; } \\
\text { 2) ownership of property rights was addressed as part of the } \\
\text { commercialisation process with focus on issues regarding } \\
\text { information in decision-making (i.e. information about } \\
\text { entrepreneurial opportunity); } \\
\text { 3) the studies included detailed and suitable theoretical framework. } \\
\text { Exclusion criteria: } \\
\text { 1) the studies did not focus on how decisions about protecting } \\
\text { technology and commercialising it are made, who is involved, what } \\
\text { kind of information is available and unavailable. } \\
\text { 2) the studies did not include detailed account of methods used. }\end{array}$ & \\
\hline 4 & Snowballing & $\begin{array}{l}\text { Snowballing of bibliographies of selected papers. Repeating stages } \\
\text { 2 and 3. }\end{array}$ & 21 \\
\hline
\end{tabular}

Source: compiled by the authors

After removing the duplicates, and conference papers, book reviews, book chapters and books (as they did not undergo the degree of scrutiny of peer review) the titles of papers were read to confirm the articles matched the general scope of the study. We dropped papers that did not focus on the commercialisation of university-generated knowledge (considering instead the development of specific technologies without explaining how it was transferred to the market or addressed the university's contribution to regional and economic development). The abstracts of the remaining 170 papers were read and those that did not address the commercialisation of university-generated knowledge or addressed the issue from the perspective of intellectual property developed by enterprises, were also excluded. At the next stage, the full texts of 59 papers were red, and those addressing the issue of information (regarding the entrepreneurial opportunity) in the commercialisation of university-generated knowledge together with property rights were included into the study, after which 25 papers were left. This was followed by snowballing that meant using the reference list of selected papers or the citations to identify additional papers (Wohlin 2014). The bibliographies of the selected papers were examined in order to find other relevant articles addressing the topic of entrepreneurial opportunity in the commercialisation of university generated knowledge. The additional papers were subjected also to steps 2 and 3 (described previously), after which 21 
additional papers remained. Following the above-mentioned selection process rendered the final account of papers to 46 .

The findings of the papers reviewed were synthesised into analytical tables, in order to identify issues regarding information conditions about the entrepreneurial opportunity and its context, in two stages. In the first stage the tables included: 1) research outcome, user involvement in research, funding sources, time, characteristics of university, property rights; 2) information about the entrepreneurial opportunity, how is the information used in the decision making process, what shapes access to information and how is it used, how to make decisions when the decision makers do not have information; 3) commercialisation, route to the market and who was involved, evidence of success. In the second stage the collected information was analysed using the previously developed analytical framework focusing at: 1) information about the entrepreneurial opportunity; 2) sources of information; 3) alternative property rights regimes.

Despite the transparency strengths of realist synthesis on account of the design of a number of distinct and explicit steps, it has also some limitations. The first issue concerns the selection of articles. The boundaries of our study are defined by the two - admittedly broad databases selected, excluding books, book chapters and conference papers. Whilst this is a common approach in literature reviews as journal papers are usually considered to represent all important contributions in a selected research area we are cognisant that it may have excluded more descriptive works from our analysis. The second limitation relates to the choice of keywords for conducting the literature search. One line of criticism could be that 
wider concepts such as "science based" AND "technology transfer"” should have been chosen instead, whilst another (opposite) view could call for further narrowness including the more directly relevant terms "information" and "entrepreneurial opportunity". As far as the former alternative is concerned our decision was influenced by Pawson et al. (2005) who state that realist synthesis employs deliberate strategies making use of purposive sampling to answer specific questions. Regarding the latter, the inclusion of those terms as initial search criteria would have excluded the vast majority of relevant papers ${ }^{7}$ (that may use similar terms like data or market or commercial opportunity). The issues regarding information were teased out in subsequent stages of the article selection process. A separate criticism, linked with the breadth of the keyword used could revolve around the balance (numerically) between papers coming from our database searches and those identified through snowballing. However, this is not uncommon in papers that use a realist synthesis approach, often identifying as many (Ellwood et al. 2017; Holkeri, 2019) or even more (Westhorp et al. 2014) from snowballing as from the original search. The final limitation relates to the scope of literature search as only the reference lists of articles, which were already identified as relevant, were looked at. The search could have been extended by including the articles, which are citing these identified papers. Our aim was, however, to locate quite specific papers, and it is an accepted practice to extend the literature search by means of snowballing using already selected papers as a starting point (Ellwood et al. 2017).

\section{BIBLIOMETRIC ANALYSIS}

\footnotetext{
${ }^{6}$ We did indeed experimented with the two aforementioned terms providing us with 50 papers from the Web of Science and 63 from Scopus, and a total of 83 after removing duplicates. Reviewing these did no add relevant papers to our study beyond those already included.

${ }^{7}$ Bibliographic searches using the terms returned just 33 papers all of which were included in the much wider search used for the purposes of our paper.
} 
Our paper includes studies published in 31 journals (Table 2), with only two (Research Policy and the Journal of Technology Transfer) having published a steady stream of research on the issue. Reviewed papers appeared in the main in science policy and technology transfer journals, whilst only two papers were published in entrepreneurship journals. Publication intensity varied through time (Figure 3): ranging between six and no papers per year. The average was just over two papers per year, which is rather low and there is no indication of it intensifying in recent years.

Table 2. Division of papers by journals

\begin{tabular}{|l|c|}
\hline Journal & $\begin{array}{r}\text { No. of } \\
\text { papers }\end{array}$ \\
\hline Research Policy & 10 \\
\hline Journal of Technology Transfer & 8 \\
\hline Journal of Management Studies & 2 \\
\hline Technovation & 2 \\
\hline American Economic Review, Annual Review of Law and Social Science, Berkeley Technology \\
$\begin{array}{l}\text { Law Journal, California Law Review, European Planning Studies, Foresight-Russia, Foundations } \\
\text { and Trends in Entrepreneurship, Industrial and Corporate Change, Industry and Innovation, }\end{array}$ \\
$\begin{array}{l}\text { Innovation: Management, Policy \& Practice, International Journal of Technology Management, } \\
\text { International Journal of Innovation and Technology Management, Journal of Business Venturing, } \\
\text { Legal Studies Research Paper Series, Management Decision, Management Science, Minerva, } \\
\begin{array}{l}\text { Oxford Review of Economic Policy, Research in Multi Level Issues, Science and Public Policy, } \\
\text { Science, Technology and Society, Stanford Technology Law Review, Technology Analysis \& } \\
\text { Strategic Management, Theory and Society }\end{array}\end{array}$ \\
\hline
\end{tabular}

Source: compiled by the authors

Figure 3. Division of papers by year of publication

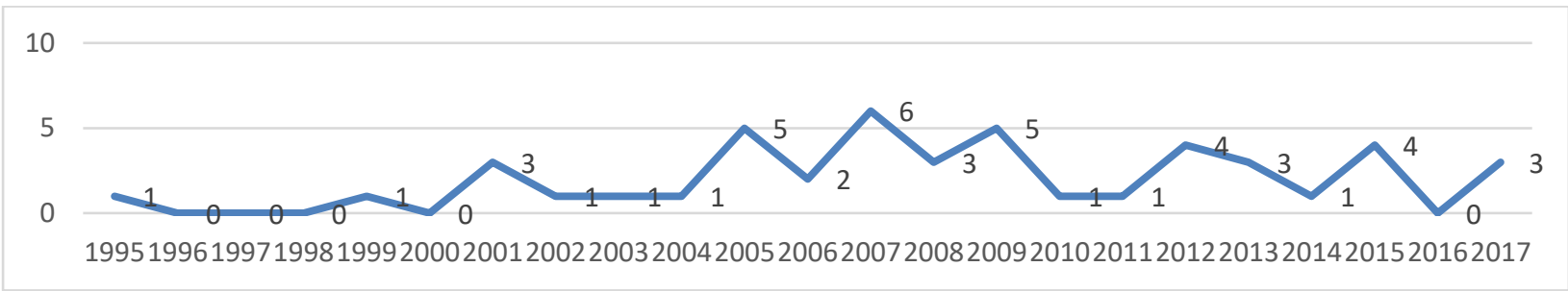

Source: compiled by the authors

The papers adopted a number of theoretical lenses depending on their context. A significant minority of papers drew on constructs revolving around intermediation and IP ownership and management (Table 3). Institutional theory was also commonly used, particularly when addressing the institutionalisation of knowledge transfer activities, isomorphism of 
organisations, path dependencies, and institutions governing and influencing commercialisation. A number of studies approached the phenomenon from the perspective of the triple helix (including offshoots such as academic entrepreneurship and the entrepreneurial university). Open innovation theory was also present in a handful of studies. Studies of university spin-offs rarely utilised the resource-based view.

Table 3. Theoretical constructs used in selected papers

\begin{tabular}{|l|l|}
\hline Theoretical construct & Studies \\
\hline Intermediation & $\begin{array}{l}\text { Ambos et al. (2008); Baldini (2009); Berbegal-Mirabent et al. (2012); Bigliardi } \\
\text { et al. (2015); Chapple et al. (2005); Ewing and Feldman (2012); Fukugawa } \\
\text { (2009); Greenbaum and Scott (2008); Markman et al. (2005); Phan and Siegel } \\
\text { (2006); Siegel et al. (2007); Thursby et al. (2001) }\end{array}$ \\
\hline $\begin{array}{l}\text { IP ownership and } \\
\text { management }\end{array}$ & $\begin{array}{l}\text { Ayres and Ouellette (2017); Colyvas et al. (2002); Giuri et al. (2013); } \\
\text { Govindaraju et al. (2009); Hertzfeld et al. (2006); Jensen and Thursby (2001); } \\
\text { Kalantaridis (2019); Lee (2012); Lessig (1999); Liyanage and Mitchell (1995); } \\
\text { Valentin and Jensen (2007) }\end{array}$ \\
\hline Institutional theory & $\begin{array}{l}\text { Geuna and Muscio (2009); Kameo (2015); Kenney and Patton (2009); O'Shea } \\
\text { et al. (2005); Owen-Smith and Powell (2001); Owen-Smith and Powell (2003); } \\
\text { Payumo et al. (2012); Rhoten and Powell (2007); West (2008) }\end{array}$ \\
\hline Triple helix & $\begin{array}{l}\text { Algieri et al. (2013); Braunerhjelm (2007); Grimaldi et al. (2011); Jeong and } \\
\text { Lee (2015); Uranga et al. (2007); Wu et al. (2015); Damsgaard and Thursby } \\
\text { (2013); Halilem et al. (2017) }\end{array}$ \\
\hline Resource-based view & Powers and McDougall (2005); Zahra et al. (2007); Vohora et al. (2004) \\
\hline Open innovation & Cervantes and Meissner (2014); Rai (2004) \\
\hline Other & Feller and Feldman (2010) \\
\hline
\end{tabular}

Source: compiled by the authors

Not surprisingly given the positivist nature of theoretical models, the methodological approaches used in the selected papers were mostly quantitative (either a survey carried out by the authors or analysis of existing data, like patent information) (Table 4). There were only seven qualitative studies drawing from interview data and case studies of technology commercialisation. There were just two studies combining the quantitative and qualitative approach. A separate strand of research revolved around literature reviews, mostly qualitative (content analysis) but also quantitative (involving citation analysis). Lastly, there was a number of conceptual papers.

Table 4. Methodological approaches used in selected papers 


\begin{tabular}{|l|l|}
\hline & $\begin{array}{l}\text { Algieri et al. (2013); Ambos et al. (2008); Baldini (2009); Berbegal-Mirabent et al. } \\
\text { (2012); Bigliardi et al. (2015); Braunerhjelm (2007); Chapple et al. (2005); Damsgaard } \\
\text { and Thursby (2013); Fukugawa (2009); Giuri et al. (2013); Govindaraju et al. (2009); } \\
\text { Halilem et al. (2017); Hertzfeld et al. (2006); Jensen and Thursby (2001); Jeong and Lee } \\
\text { (2015); Markman et al. (2005); O'Shea et al. (2005); Powers and McDougall (2005); } \\
\text { Zahra et al. (2007); Thursby et al. (2001); Valentin and Jensen (2007); Wu et al. (2015) }\end{array}$ \\
\hline Quantitative & $\begin{array}{l}\text { Colyvas et al. (2002); Feller and Feldman (2010); Kameo (2015); Owen-Smith and } \\
\text { Powell (2001); Payumo et al. (2012); Rai (2004); Vohora et al. (2004) }\end{array}$ \\
\hline Mixed methods & Kalantaridis (2019); Owen-Smith and Powell (2003) \\
\hline Literature review & $\begin{array}{l}\text { Geuna and Muscio (2009); Phan and Siegel (2006); Siegel et al. (2007); Uranga et al. } \\
\text { (2007) }\end{array}$ \\
\hline Conceptual & $\begin{array}{l}\text { Ayres and Ouellette (2017); Cervantes and Meissner (2014); Ewing and Feldman (2012); } \\
\text { Greenbaum and Scott (2008); Grimaldi et al. (2011); Kenney and Patton (2009); Lee } \\
\text { (2012); Lessig (1999); Liyanage and Mitchell (1995); Rhoten and Powell (2007); West } \\
\text { (2008) }\end{array}$ \\
\hline
\end{tabular}

Source: compiled by the authors

\section{CONTENT ANALYSIS}

\subsection{Information about the Entrepreneurial Opportunity}

In this sub-Section we will address the first question of our analytical framework concerning the types of information regarding entrepreneurial opportunity employed in commercialisation decisions (Figure 2). There is very little empirical research exploring instances defined by ambiguity, i.e. where the pursuit of information about the entrepreneurial opportunity revolves around matching scientists and firms. In this generalised context, Braunerhjelm, (2007) and Govindaraju et al. (2009) stress the importance of information about markets and the outcomes of market research and analysis for commercialisation and conclude that decisions are often made when information of this type, though knowable, is absent.

There is a larger body of research exploring contexts defined by uncertainty. Siegel et al. (2007) and Baldini (2009), highlight the importance of the information needed in order to evaluate the commercial potential of IP: including the degree of scientific, legal and commercial novelty, the costs and benefits of alternative commercialisation routes, and the establishment of profitability. Empirical evidence, concurring with theorisation in 
entrepreneurial studies, questions the knowability of information around the entrepreneurial opportunity (Siegel et al. 2007; Uranga et al. 2007; Kenney and Patton 2009; Cervantes and Meissner 2014; Jeong and Lee 2015; Kalantaridis 2019). More specifically, Owen-Smith and Powell (2003) use a quote from a TTO who states that '[i]n most cases you don't even have a prototype, let alone an established market. So going out and saying 'what's the potential market for this technology,' doesn't work for most of the technologies we deal with. We're often hard put even to figure out what the product is going to be, let alone determine market size' (ibid. 1706).

This body of research strongly supports the view that uncertainty, in the case of licensing to established firms, may be sector and discipline specific. Valentin and Jensen (2007) show that in the biotechnology and science based sectors this occurs at a very early stage: therefore, there is not sufficient information about the entrepreneurial opportunity to evaluate its commercial potential leading often to failure to exploit it. West (2008) also suggest that licensing in science-based contexts is not influenced by early research collaboration, or the identification of licensees before patenting, but benefits from the researcher's post-disclosure engagement ${ }^{8}$.

\subsection{Actors and Information Conditions}

In this sub-section the research question regarding the actors that shape the information conditions related to the entrepreneurial opportunity is addressed. The bulk of the accumulated literature, in line with prevailing theoretical constructs, stresses the centrality of TTOs in both contexts. In instances of ambiguity TTOs identify opportunities for start-ups

\footnotetext{
${ }^{8}$ They contrast this with engineering based IP, where ambiguity prevails, where research is inherently more interdependent with practice with individuals being able to straddle and process information across the academic and enterprise domains.
} 
(Payumo et al. 2012), and facilitate the flow of information to academics (Giuri et al. 2013). In this setting, according to Aldrich and Fiol (1994), TTOs may act, in addition to being enablers of patenting, licensing and start-ups, as institutional entrepreneurs in building legitimacy for novel technologies, and by fulfilling three distinct roles: protector, propagator and influencer of the novel technology (Siegel et al. 2007). In the context of uncertainty, Siegel at al. (2007) emphasise their role in dealing with the evaluation of inventions (i.e. once they are disclosed).

However, our review suggests that the ability of TTOs to shape information conditions is influenced by their individual histories. Particularly relevant for contexts of uncertainty, Owen-Smith and Powell (2001) argue that all-but-one TTOs that they surveyed lacked experience in identifying patentable technologies. They go on to contend that formal technology transfer experience helps the assessment of information and the evaluation of invention disclosures. Siegel et al. (2007) also claim that the skill-base of TTOs must extend beyond the ability to provide legal advice regarding the protection of IP to experience in opportunity recognition and other commercial exploitation skills. This is a view supported by entrepreneurs frustrated by TTOs lack of market knowledge (Wu et al. 2015). Similarly, Hertzfeld et al. (2006) state in a survey of US-based IP attorneys, established firms may express great difficulty in dealing with university TTOs on account of the relative inexperience of the latter in terms business knowledge and tendency to overstate the value involved in university-owned IP. At the individual case level Reid (1997) shows that when Andreessen and Clark formed Netscape in 1994 and tried to negotiate a license with the University of Illinois they have found the process so frustrating that they rewrote the browser code entirely. 
Other research, more relevant in contexts defined by ambiguity, stresses the particular importance of personal histories in providing TTOs with the personal contacts, with established firms, needed in accessing opportunities (Lee 2012). This view is also supported by $75 \%$ of TTOs participating in survey conducted by Thursby et al. (2001) in the US. In the same context, Powers and McDougall (2005) state that more experienced TTOs are able to establish better routines to support start-up commercialisation, a view also supported by Algieri et al. (2013). Berbegal-Mirabent et al. (2012) also identify a positive and statistically significant relationship between the years of experience in the TTO role and start-up success. Only Ambos et al. (2008) suggest that greater experience does not affect commercialisation.

The presence of a formal technology transfer office itself, the effect of scale of university research and its IP portfolio, is generally viewed as important for commercialisation success (Markman et al. 2005; Phan and Siegel 2006; Baldini 2009). Geuna and Muscio (2009) take this point further, suggesting that the attainment of critical mass influences the ability of the office to be effective in performing its different tasks. O'Shea et al. (2005) find that the number of TTOs in technology transfer offices is positively related to the spin-off creation rate. Fukugawa (2009) explains that this may be on account of the accumulation of skilled staff but caution that office maturity may bring institutionalisation and the adoption of a more risk-averse approach. A subtly different view is advanced by Bigliardi et al. (2015) who focus on the experience accumulated in the technology transfer office through time. Kenney and Patton (2009) also lend support to positive effects of size arguing that offices that are too small and lack sufficient well-qualified personnel could lead to the development of a negative reputation with enterprises. They attribute the importance of size arguing on the fact that whilst enterprises usually develop absorptive capacity in a very narrow sectoral setting (where the core of their business is based), universities do so across a number, at times tens, 
of Departments each operating in a distinct disciplinary and sectoral setting. Thus, they have to develop absorptive capacity across a variety of fields. Interestingly, the importance of specialism leads Chapple et al. (2005) to argue that large offices may suffer from diseconomies of scale or the problem of being generalist in approach, thus, calling for the creation of smaller and more specialist technology transfer offices.

This point has implications for the theoretical models reviewed earlier in the paper. This is because it stresses the importance of differentiation and it implications on the ability of TTOs in order to operate in different sectoral and disciplinary contexts. A relaxation of the assumption, by Hoppe and Ozdenoren (2005) and Hellman (2005), about the undifferentiated nature of the science and IP base of universities (that seems necessary in light of our previous findings), is going to result to a higher, than what predicted in these studies, number of patents in order to justify investment in intermediation expertise. This, in turn, may explain why universities engage increasingly in collaboration with each other and with nonpracticing entities in commercialisation. Regarding the former, Cervantes and Meissner (2014) report that the UK Intellectual Property Office adopted a proposal from a number of leading universities (such as Glasgow, Bristol and King's College London) to develop an Easy Access Innovation Partnership, whilst in France, the French National Research Agency has established a fund to create Technological Transfer Acceleration Companies in order to reduce fragmentation of TTO services at the regional level. Regarding the latter, there is growing evidence that universities in the United States increasingly license their intellectual properties to nonpracticing entities in order to maximise income (for example CIT, University of California, University of Bristol, National University of Singapore, University of Texas and others) (Ewing and Feldman 2012); whilst universities in emerging knowledge producing countries (such as Brazil and India) increasingly co-operate with them as a means 
of accessing users beyond the confines of their national boundaries (Ewing and Feldman 2012; Kalantaridis et al. 2017). These are organisations that own and often assert IPRs but do not directly exploit in practice the knowledge covered by the IPRs (Meurer and Bessen 2014). They may possess very large patent portfolios, the largest has amassed 30,000-60,000 patents worldwide (Ewing and Feldman 2012), in comparison to those held by individual universities.

There is a modest body of research pointing at the role of academics in shaping information conditions around the entrepreneurial opportunity. In information conditions of ambiguity, particularly in relation to licensing to established firms there is a strong current of opinion claiming that academics lack market information (Valentin and Jensen 2007). Similarly, West (2008) argues that commercialisation is often delayed because of a scarcity of know-why among top researchers, pursuing a real-world problem that matched their theory's assumptions. Interestingly however, he goes on to argue that the role of support functions (including TTOs) is really important in enhancing the market-orientation of academics. The involvement of academics in the commercialisation process is particularly important for success in instances where commercialisation is realised through the creation of a university spin-off (Damsgaard and Thursby 2013). For academic spin-offs it is important to 'meet the demands of the market and ... have a fit to an existing opportunity independent from the context the spinoff emanates from' (Helm et al 2018). In a manner reminiscent of the argument developed previously about the importance of past contacts in the case of TTOs, Braunherjelm (2007) and Lee (2012) stress the importance of the network of relationships held by the academic, as a means of creating a new set of linkages with market-based agents (primarily established firms). This facilitates access to information about the entrepreneurial opportunity. This view is also supported by Kameo (2015) who argues that even after the 
adoption of the Japanese equivalent of the Bayh-Dole Act, the academic-industry relations persisted to be more important than inventor-TTO relations. Rhoten and Powell (2007) go on to argue that such relationships enable 'individual scientists ... to act as amphibious creatures, moving back and forth as consultants and advisors and as founders of university spin-off firms' (ibid. 356).

The importance of heuristics and the experience (contexts of uncertainty) needed in order to realise the commercial opportunity involved in creation (information conditions of uncertainty) is also highlighted in the literature (Valentin and Jensen 2007). This view is supported by Uranga et al. (2007) who centre on the entrepreneurial know-how of academics regarding market expectations. However, Zahra et al. (2007) are sceptical about the ability of academic inventors to act entrepreneurially. The authors show that company spin-offs surpass their university counterparts in the conceptualisation and visioning capabilities needed for commercialisation. To counter this, Vohora et al. (2004) state that academics need to engage in a highly complex process of learning about accessing and processing information about the entrepreneurial opportunity in order to engage effectively in commercialisation.

There is precious little work examining the role of established firms in shaping information conditions. Existing research focuses on contexts of ambiguity and stresses the importance of sustained linkages between firms and academics (rather than TTOs) in transmitting information about market needs (Colyvas et al. 2002; Wu et al. 2015). Owen-Smith and Powell (2003) also present evidence that emphasises 'the central role that firms play as a source of information that enables effective evaluation of the potential of often ambiguous faculty innovations' (ibid. 1707). They usefully quote a TTO who claims that: 'We have very good pipelines into the biotech world, we know who is doing what in cancer, who is working 
in auto-immune, etc. and we go to these companies and get a quick response. There is nothing equivalent on the physical science side' (ibid. 1705). Feller and Feldman (2010) provide six case histories of new technical knowledge developed at Penn State University, whose evolution into commercialised products was influenced in large part by the information input of enterprises engaged in the process (particularly pertinent is the case of the heart assist devices). Owen-Smith and Powell (2003) go on to argue that firms that specialise in technology transfer are better equipped to engage in commercialisation. More specifically, they (2003) content that firms of this type can provide universities with the tools needed in order to evaluate research outcomes disclosed through the eyes of potential entrepreneurs and investors. However, Owen-Smith and Powell (2003) warn that the flipside of this is that strong linkages between a university and a small number of enterprises of this type may result in a form of capture of its research outcomes, ultimately leading to decline in returns on its patent portfolio.

There is much less research exploring the role of established enterprises in information conditions of uncertainty. Specifically, Kalantaridis (2019) argues that there is no formal role assigned to users (enterprises) in making commercialisation decisions about disclosures, even though TTOs acknowledge that 'in the infrequent instances where informal entrepreneurial feedback is sought "from people we feel confident we know" TTOs recognise that this could be "quite transformational” (Joe, TTO)' (ibid. 14). Liyanage and Mitchell (1995) confirm that industry representatives are frustrated in their exclusion and lack of influence from the direction of research outcomes towards commercial exploitation and utility.

\subsection{Property Rights and Information about the Entrepreneurial Opportunity}


This empirical subsection addresses the third research question about how the roles and rights of actors influence information conditions regarding the entrepreneurial opportunity. The issue of the prevailing property rights features prominently in the university commercialisation literature, and revolves around three competing regimes. University ownership constitutes the dominant property rights regime in the US and most of Europe (Grimaldi et al. 2011). Within this context, the university is conferred with rights upon the research outcomes produced by academics through public funding, and undertakes the task of promoting this to users who can adopt it for the purposes of introducing innovation. Concerns about the ability of this regime to deliver optimal solutions, as described in the introductory Section of our paper, prompted the advancement of two correctives. The first, advanced by Ayres and Oullette (2017) proposes a 'market test' for university inventions, whereby, before charging licensing fees universities would be required to find out whether enterprises would be willing to commercialise the invention in return for a nonexclusive license with a nominal fee. This would, according to the authors, be particularly useful in advancing commercialisation when there are multiple users interested in university held IP, and reduce aggressive litigious behaviour by universities. A different corrective is advanced by Lee (2012) who argues that increased integration, though a plethora of formal and informal linkages, is an essential complement to university ownership on account of the tacit element of the IP involved. An altogether different, and competing, to university ownership property rights regime involves inventor ownership. This regime that was present in a number of European countries, such as Denmark, Sweden, and Italy places the actor who is most (technically) knowledgeable about the research outcome in the position of deciding the approach to commercialisation (Kenney and Patton 2009). This is viewed as a means of strengthening academic entrepreneurship and decentralising knowledge transfer, facilitating effective and quick diffusion and maximizing innovation and development outputs (Kenney 
and Patton 2011). Inventor ownership has been found to have a positive impact on generating spinoffs rather than on licensing (Damsgaard and Thursby, 2013; Kenney and Patton, 2011). The third competing property rights regime revolves around the development of a commons: i.e. a self-organising community of actors that creates rules that specify the rights and responsibilities of its members regarding the use of a resource that is accessible for all those involved in the community (Hess and Ostrom 2003). This is conceptualised in two distinct ways in the literature: one which focuses on open access and limited proprietisation (Lessig 1999; Rai 2004; Kenney and Patton 2009; Cervantes and Meissner 2014), and another that centres on social structures developed for the management of a shared resource (Ostrom 2010). A commons type of solution constitutes a property rights regime that affords entrepreneurs the ability to engage in the transition from disclosure to patenting whilst maintaining the involvement of the academic-inventor. Unlike inventor ownership it does not confer rights to an actor early in the transition from disclosure to patent, whilst, unlike open access, it allows for the protection of the rights of members (of the commons) from nonmembers.

In a suggestive contribution to the debate Halilem et al. (2017) adopt a more subtle approach to property rights regimes differentiating between ownership rights, control rights, and income-sharing rights. Their empirical findings support this disaggregation as they show that contrary to the bulk of the literature, the behaviour of academics is influenced not by ownership rights but by control rights, and the sharing of income with the university. These findings have potentially significant implications for the importance of ownership as a means of encouraging academics to disclose new technical information coming from publicly funded research. This, in turn, opens up the scope for the use of Ostrom's (2010) distinction 
of bundle of property rights (differentiating between access, withdrawal, management, exclusion, and alienation) in the study of university commercialisation.

There is, however, a relatively modest amount of research exploring directly the effects of the prevailing property rights regime on the information conditions around the entrepreneurial opportunity in commercialisation. This research often compares information conditions under university ownership with those under inventor ownership. These studies show that the prevailing regime strengthens the rights of TTOs, affording them a dominant position in decision-making in comparison to the two other types of actors (the academics and the firms). Specifically, Valentin and Jensen (2007) show that following the introduction of university ownership (replacing inventor ownership in 2000) in Denmark, there has been a steep decrease in the number of academics involved in patents owned by dedicated biotechnology firms (where uncertainty is a key consideration). Damsgaard and Thursby (2013), comparing university ownership in the United States with inventor ownership in Sweden illustrate that if there are search costs in finding an established firm for licensing the average probability of commercialisation success is instead higher in the latter regime. They content that this may be linked to the centrality of the TTO in making the decision as to whether and how to commercialise in the US in comparison to the academic in Sweden. These findings support the conclusions of the theoretical constructs discussed earlier in the paper: that argue that the emergence of intermediaries (TTOs) will result in academics leaving commercialisation in the hands of the TTOs and remaining focused on their research and teaching duties (Hoppe and Ozdenoren 2005; Hellman 2005).

The prevailing property rights regime means that firms are excluded from the decision regarding which research outcomes to protect and invest in their further development 
(Kalantaridis 2019). This is because this decision remains internal to the university (Kalantaridis 2019). Indeed, there is a wealth of empirical evidence showing that this decision rests heavily with TTOs (Owen-Smith and Powell 2001; Siegel et al. 2007; Kenney and Patton 2009; Wu et al. 2015). This despite the fact that entrepreneurs leading firms are better equipped in terms of heuristics and experience in evaluating and exploiting commercial opportunities than TTOs: as shown empirically (Owen-Smith and Powell 2003) Valentin and Jensen 2007; Kalantaridis 2019).

\section{DISCUSSION}

Our paper shows that information conditions about the entrepreneurial opportunity have attracted modest attention in the study of the commercialisation of university IP. This is, in the main, because the fundamental challenge around commercialisation was perceived to be one of mobilising research outcomes and engaging the academic in supporting innovation. There is particularly little research revolving around RQ1, examining the types of information used, as this is by its nature descriptive and, thus, less attractive for the international, peer-reviewed journals included in the two databases used in our study. This is especially the case regarding research examining the specifics of information about the entrepreneurial opportunity in contexts of ambiguity. Instead, the bulk of published work focuses on, and evidences the importance of, information about the entrepreneurial opportunity in contexts of uncertainty and ascertains the types (of information) needed in the decision-making process. This body of research illustrates the challenges confronting actors, and particularly TTOs, in making decisions in such contexts.

Evidence from the studies reviewed here challenges the assumption underpinning theoretical modelling about the undifferentiated nature of university held IP. Indeed, sector and 
discipline, and the distinct nature of synthetic or analytic knowledge, are defining in determining whether information conditions of ambiguity or uncertainty prevail. This supports the development of our paper's first proposition:

P1: The IP held by universities is differentiated by sector and discipline into two distinct information conditions: one defined by ambiguity and another defined by uncertainty.

The introduction of differentiation means that the attainment of scale that would justify the cost of commercialisation is greater than originally envisaged (in theory): and may be in fact linked with the disciplinary breadth (e.g. the number of Departments of individual universities). In response, we believe that a corrective is needed in order to accommodate differentiation in prevailing theoretical constructs and explore its implications on the scale that must be attained by universities (see A in Figure 4). As a result, the attainment of this scale may be beyond the reach of many universities, not only small and medium-sized but also larger ones (that may also have considerable disciplinary breadth). This may begin to offer an explanation as to why universities increasingly develop linkages with nonpracticing entities or pursue collaborative arrangements with other universities, often - but not solely in a regional context. Further empirical research into these linkages/ collaborations, probably using case study methods, can provide insights into the practice and implications of alternative arrangements (involving a more complex network of participants) on information conditions about the entrepreneurial opportunity. Research on the latter could usefully delve qualitatively into the nature of such arrangements ( $\mathrm{C}$ in Figure 4) as well as quantitatively on their effects on the attainment of positive (and negative - in the form of litigation actions) commercialisation outcomes (B in Figure 4).

\section{Figure 4. Analytical Framework and Emerging Research Agenda.}




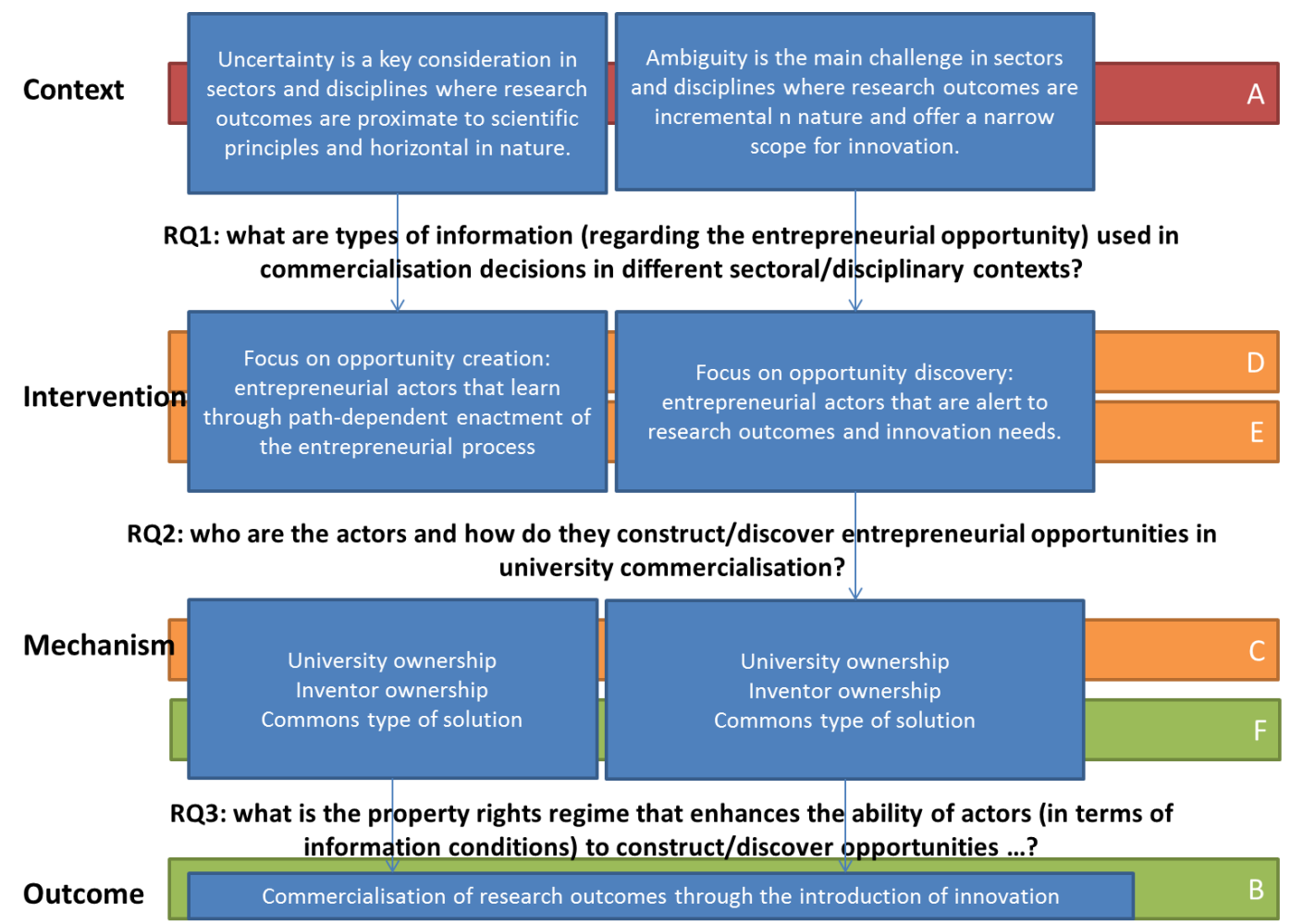

Conceptual

Qualitative methods

Quantitative methods

On the question regarding the actors that shape information conditions about the entrepreneurial opportunity (RQ2) published research lends support to the primacy attached by theoretical models to TTOs at the expense of academics and firms. Placing the results of past research in the definitional mould of the entrepreneurial function presented in the second section of the paper, it is apparent that it is TTOs who perform the entrepreneurial function in the transition from research outcome to IP. However, what TTOs do and the expertise they need to perform this function differs between information conditions of ambiguity and uncertainty. In line with theoretical research from the field of entrepreneurial studies (Kirzner 1973) empirical evidence suggests that in the former conditions alertness to opportunities to perform a matching/brokerage function, and thus, experience in processing information that is available to them are key. In the latter type of information conditions TTOs cognitive biases (such as the willingness to learn from failed experiments) that are the result of path- 
dependent enactment processes, and particularly previous experience of entrepreneurial venturing, are central for success (Alvarez et al. 2013). Moreover, there is a voluminous body of empirical research suggesting that TTOs do not possess the experiences needed in order to perform particularly the function required in information conditions of uncertainty. Thus, we adopt a critical perspective to the strengthening of the role of TTOs in commercialisation - in contrast to the rest of the empirical and theoretical literature. This leads to develop our second proposition:

P2: TTOs need different types of expertise in order to act entrepreneurially in information conditions of ambiguity and uncertainty.

This has implication both regarding the direction of future research and the proposed intervention. Regarding the former it calls for the conduct of more qualitative research that may provide depth of understanding on how actors discover and create entrepreneurial opportunities (D in Figure 4). This could be particularly important given the overwhelmingly quantitative character of existing research despite the rich insights gained by the handful of qualitative case studies (for an excellent example see Feller and Feldman 2010). Moreover, it affords greater flexibility in the assignment of the entrepreneurial function to actors involved in commercialisation. Depending on the context this could be either the TTO (ambiguity) or an academic (potentially in partnership with an entrepreneur) in the case of a spin-off or an entrepreneur from an established firm (uncertainty) (E in Figure 3). However, this questions the appropriateness of the deployment of the same intervention in both contexts. Indeed, the very different attributes identified in theoretical constructs regarding opportunity discovery and creation pose the question of whether the same individual (TTO or academic or entrepreneur) could perform the entrepreneurial function in different contexts. 
Rather surprisingly, there is precious little research on the implications of property rights on information conditions about the entrepreneurial opportunity (RQ3). The handful of studies exploring this support the view advanced in theory by Hoppe and Ozdenoren (2005), MachoStaedler et al. (2007) and Hellmann (2005) that it is university ownership that defines the enhanced role of TTOs. At the same time though, university ownership excludes firms (and by implication practicing entrepreneurs), with their ability to deal with information conditions in contexts of uncertainty, from decisions taken in the transition from disclosure to patenting. This leads us to advance our final proposition:

P3: In information conditions of uncertainty property rights regimes must afford a role to practicing entrepreneurs in the creation of the entrepreneurial opportunity.

Alternative property rights regimes may impact the relative importance of these two actors (in relation to TTOs) in this transition. Viewed in an abstract manner a commons type of solution may enhance the contribution of entrepreneurs, whilst inventor ownership may effect no change, unless the academic inventor also acts as the entrepreneur (a view implicitly acknowledged in part of the literature reviewed in our paper). Empirical research involving the conduct of experiments (to test actor behaviour in the context of different regimes) is needed to explore the implications of these two alternatives ( $F$ in Figure 4). This may be usefully informed by more subtle conceptualisations of property rights regimes: either differentiating between ownership, control and income share or adopting the more disaggregated Ostromian approach. Also differentiation in the effectiveness of distinct property rights regimes in information conditions of ambiguity and uncertainty may be usefully explored using the same methods. The implications of this research for practice may also be profound.

A charge levelled against the research agenda advanced here, a per the criticism raised by Kitching and Rouse (2017) against studies of the entrepreneurial opportunity, may be that it 
is paradigmatically confused, in the sense that some of the directions identified can best be pursued within the ontological and epistemological assumptions of positivism (A, C, F) others of critical realism (B, C) and even interpretivism (D, E). Instead, we argue that our agenda can be usefully advanced by a community that is more diverse paradigmatically, methodologically and theoretically than is the case now that is explicit about the assumptions and definitions used.

\section{CONCLUSIONS}

Our, and first, systematic review of the literature focusing on information conditions regarding the entrepreneurial opportunity shows that key conclusions of existing theoretical constructs, particularly those revolving around the emergence of TTOs as the main intervention and the importance of university ownership for their ability to do so, are supported by the outcomes of published research. However, the papers reviewed here also illustrate profound challenges confronting TTOs, partly on account of the different types of expertise needed in order to act in conditions of ambiguity and uncertainty and partly due to their lack of appropriate expertise in the context of uncertainty. The latter challenge is intensified by the fact that firms, and their entrepreneurs, who are well equipped in terms of expertise to make decisions in contexts of uncertainty are excluded from the transition between disclosure and patenting. These, in turn, pose questions about not only the appropriateness of the intervention but also in terms of whether the same intervention can produce positive outcomes, in transforming research outputs to innovation, in different information conditions. Moreover, our paper also suggests that significant gaps in our knowledge, and thus our ability to act, remain. This is because published research has been narrow in scope: i.e. confined within the paradigmatic and methodological boundaries of early theorisation and the ensuing intervention. 
Ultimately our paper calls for a review of the policy consensus and actions of the 1980s that still define commercialisation. At that time, the response to the question of how best to commercialise the outcomes of academic research was unequivocal: i.e. to place universities centre stage. They were viewed as the organisational structures that would, if incentivised appropriately, invest in acquiring the expertise and bearing the cost of information needed to achieve this result. Consequently, universities grew rapidly their patent portfolio and created technology transfer offices. However, universities still succeed in commercialising only a fraction of their IP. Insights of research exploring information conditions regarding the entrepreneurial opportunity shows that the original problem (and solution) may need to be revisited through a different perspective: one that is more conventional, in the wider context of entrepreneurial action. To do so will need evidence coming from a broader, both theoretically and methodologically, body of research than is the case currently. More importantly, however, we also contend that the new response to this 'old problem' may not be singular and unequivocal. Sensitivity to the specificities of sector and discipline may produce more subtle but potentially more effective solutions.

The authors would like to express their thanks to the two anonymous reviews for the detailed and constructive comments to the original.

\section{BIBLIOGRAPHY}

Abrams, I., Leung, G., \& Stevens, A. J. (2009). How are US technology transfer offices tasked and motivated - is it all about money? Research Management Review, 17, 1-34.

Aldrich, H. E., \& Fiol, C. M. (1994). Fools rush in? The institutional context of industry creation. Academy of Management Review, 19(4), 645-670.

Algieri, B., Aquino, A., \& Succurro, M. (2013). Technology transfer offices and academic spin-off creation: the case of Italy. Journal of Technology Transfer, 38, 382-400. 
Alvarez, S. A. and Barney, J. B. (2007). Discovery and creation: Alternative theories of entrepreneurial action. Strategic Entrepreneurship Journal, 1(1-2), 11-26. Alvarez, S.

Barney, J. B., \& P. Anderson. 2013. Forming and Exploiting Opportunities: The Implications of Discovery and Creation Processes for Entrepreneurial and Organizational Research.

Organization Science, 24(1), 301-317.

Ambos, T., Mäkelä, K., Birkinshaw, J., \& D'Este, P. (2008). Creating Ambidexterity in Research Institutions. Journal of Management Studies, 45, 1424-1447.

Asheim, B. T., \& Coenen, L. (2005). Knowledge base and regional innovation systems: Comparing Nordic clusters. Research Policy, 34(8), 1173-1190.

Asheim, B. T., \& Gertler, M. S. (2005). The Geography of Innovation: Regional Innovation Systems. In J. Fagerberg, D. C. Mowery \& R. R. Nelson (Eds.) The Oxford Handbook of Innovation (291-317). Oxford: Oxford University Press.

Ayres, I., \& Ouellette, L. L. (2017). A Market Test for Bayh-Dole Patents. Cornell Law Review, 271-334.

Baldini, N. (2009). Implementing Bayh-Dole-like laws: Faculty problems and their impact on university patenting activity. Research Policy, 38(8), 1217-1224.

Battistella, C., De Toni, A. F., \& Pillon, R. (2016). Inter-organisational technology/knowledge transfer: a framework from critical literature review. The Journal of Technology Transfer, 41(5), 1195-1234.

Berbegal-Mirabent, J., Sabaté, F., \& Cañabate, A. (2012). Brokering knowledge from universities to the marketplace: The role of knowledge transfer offices. Management Decision, 50(7), 1285-1307.

Bigliardi, B., Galati, F., Marolla, G., \& Verbano, C. (2015). Factors affecting technology transfer offices' performance in the Italian food context. Technology Analysis \& Strategic Management, 27(4), 361-384.

Braunerhjelm, P. (2007). Academic entrepreneurship: social norms, university culture and policies. Science and Public Policy, 34(9), 619-631.

Burt, R. S. (2000). The network structure of social capital. Research in Organizational Behavior, 22, 345-423.

Burt, R. S. (2004). Structural holes and good ideas. American Journal of Sociology, 110(2), 349-399.

Cervantes, M., \& Meissner, D. (2014). Commercialising public research under the open innovation model: new trends. Foresight, 8(3), 70-81.

Chapple, W., Lockett, A., Siegel, D., \& Wright, M. (2005). Assessing the relative performance of UK university technology transfer offices: parametric and non-parametric evidence. Research Policy, 34(3), 369-384.

Chen, Y. Bin, Liu, J. S., \& Lin, P. (2013). Recent trend in graphene for optoelectronics. $J$. Nanoparticle Res, 15(145), 1-14. 
Colyvas, J., Crow, M., Gelijns, A., Mazzoleni, R., Nelson, R. R., Rosenberg, N., \& Sampat, B. N. (2002). How do university inventions get into practice? Management science, 48(1), 61-72.

Damsgaard, E. F., \& Thursby, M. C. (2013). University entrepreneurship and professor privilege. Industrial and Corporate Change, 22(1), 183-218.

Davidsson, P. (2015). Entrepreneurial opportunities and the entrepreneurial nexus: A reconceptualization. Journal of Business Venturing, 30, 674-695.

Denyer, D., Tranfield, D., \& Aken, van J. E. (2008). Developing Design Propositions through Research Synthesis. Organization Studies, 29(3), 393-413.

Denyer, D., \& Tranfield, D. (2009). Producing a systematic review. In D. A. Buchanan \& A. Bryman (Eds.) The Sage handbook of organizational research methods (671-689). Thousand Oaks, CA: Sage Publications Ltd.

Ellwood, P., Grimshaw, P., \& Pandza, K. (2017). Accelerating the innovation process: a systematic review and realist synthesis of the research literature. International Journal of Management Reviews, 19(4), 510-530.

Ewing, T., \& Feldman, R. (2012). The giants among us. Stanford Technology Law Review, 1, $1-64$.

Feller, I., \& Feldman, M. (2010). The commercialization of academic patents: black boxes, pipelines and Rubik's cubes. Journal of Technology Transfer, 35, 597-616.

Fukugawa, N. (2009). Determinants of licensing activities of local public technology centers in Japan. Technovation, 29(12), 885-892.

Geuna, A., \& Muscio, A. (2009). The Governance of University Knowledge Transfer: A Critical Review of the Literature. Minerva, 47, 93-114.

Giuri, P., Munari, F., \& Pasquini, M. (2013). What determines university patent commercialization? Empirical evidence on the role of IPR ownership. Industry and Innovation, 20(5), 488-502.

Govindaraju, V. C., Ghapar, F. A., \& Pandiyan, V. (2009). The role of collaboration, market and intellectual property rights awareness in university technology commercialization. International Journal of Innovation and Technology Management, 6(4), 363-378.

Greenbaum, D., \& Scott, C. (2010). Hochschullehrerprivileg - a modern incarnation of the professor's privilege to promote university to industry technology transfer. Science, Technology and Society, 15(1), 55-76.

Grimaldi, R. Kenney, M. Siegel, D. S., \& Wright, M. (2011). 30 years after Bayh-Dole: Reassessing academic entrepreneurship. Research Policy, 40(8), 1045-1057.

Halilem, N., Amara, N., Olmos-Peñuela, J., \& Mohiuddin, M. (2017). To Own, or not to Own? A multilevel analysis of intellectual property right policies' on academic entrepreneurship. Research Policy, 46(8), 1479-1489.

Hayek, F. A. (1945). The use of knowledge in society. The American Economic Review, 35(4), 519-530. 
Hellmann, H. L. (2005). The role of patents in bridging the science to market gap. NBER Working Papers, Working Paper 11460.

Helm, R., Mauroner, O., \& Pöhlmann, K. (2018). Towards a better understanding of performance measurements: the case of research-based spin-offs. Review of Managerial Science, 12(1), 135-166.

Hertzfeld, H. R., Link, A. N., \& Vonortas, N. S. (2006). Intellectual property protection mechanisms in research partnerships. Research Policy, 35(6), 825-838.

Hess C., \& Ostrom, E. (2003). Ideas, Artifacts and Facilities: Information as a Common-Pool Resource. Law and Contemporary Problems, 66, 111-145.

Hoeffer, S. (2003). Measuring preferences for really new products. Journal of Marketing Research, 40(4), 406-420.

Holkeri, J. (2019). Outsourcing of aviation technical services-a literature survey. Journal of Quality in Maintenance Engineering.

Holloway, S. S., van Eijnatten, F. M., Romme, A. G. L., \& Demerouti, E. (2016). Developing actionable knowledge on value crafting: a design science approach. Journal of Business Research, 69(5), 1639-1643.

Hoppe, H., \& Ozdenoren, E. (2005). Intermediation in Innovation. International Journal of Industrial Organization, 23, 483-503.

Jensen, R., \& Thursby, M. (2001). Proofs and prototypes for sale: The licensing of university inventions. American Economic Review, 91(1), 240-259.

Jeong, S., \& Lee, S. (2015). Strategic timing of academic commercialism: evidence from technology transfer. The Journal of Technology Transfer, 40(6), 910-931.

Kalantaridis, C., Küttim, M., Govind, M., \& Sousa, C. (2017). How to commercialise university-generated knowledge internationally? A comparative analysis of contingent institutional conditions. Technological Forecasting and Social Change, 123, 35-44.

Kalantaridis, C. (2019). Is university ownership a sub-optimal property rights regime for commercialisation? Information conditions and entrepreneurship in Greater Manchester, England. The Journal of Technology Transfer, 44(1), 231-249.

Kameo, N. (2015). Gifts, donations, and loose coupling: responses to changes in academic entrepreneurship among bioscientists in Japan. Theory and Society, 44(2), 177-198.

Kenney, M., \& Patton, D. (2009). Reconsidering the Bayh-Dole Act and the current university invention ownership model. Research Policy, 38, 1407-1422.

Kenney, M., \& Patton, D. (2011). Does inventor ownership encourage university researchderived entrepreneurship? A six university comparison. Research Policy, 40(8), 1100-1112.

Kirchberger, M. A., \& Pohl, L. (2016). Technology commercialization: a literature review of success factors and antecedents across different contexts. The Journal of Technology Transfer, 41(5), 1077-1112. 
Kirzner, I. M. (1973). Competition and Entrepreneurship. Chicago: Chicago University Press.

Kitching, J. \& Rouse, J. (2017). Opportunity or dead end? Rethinking the study of entrepreneurial action without a concept of opportunity. International Small Business Journal, 35(5), 558-577

Knight, F. H. (1921). Cost of production and price over long and short periods. Journal of Political Economy, 29(4), 304-335.

Ledford, H. (2013). Universities struggle to make patents pay. Nature, 501, 471-472.

Lee, P. (2012). Transcending the tacit dimension: Patents, relationships, and organizational integration in technology transfer. California Law Review, 1503-1572.

Lemley, M. (2008). Are Universities Patent Trolls? Fordham Intellectual Property, Media and Entertainment Law Management Journal, 18, 1-20.

Lessig, L. (1999). The limits in open code: regulatory standards and the future of the net. Berkeley Tech. LJ, 14, 759-770.

Levit, B. \& March, J. G. (1988). Organizational Learning. Annual Review of Sociology, 14, 319-340.

Liyanage, S., \& Mitchell, H. (1995). Management of intellectual property rights in Australian Cooperative Research Centres. International Journal of Technology Management, 10(2-3), 343-364.

Maassen, P., Andreadakis, Z., Gulbradsen, M., \& Stensaker, B. (2019). The Place of Universities in Society, Global University Leaders Council, Hamburg.

Macho-Stadler, I. Perez-Catrillo, D., \& Veugelers, R. (2007). Licensing of university innovations: the case of a technology transfer office. International Journal of Industrial Organization, 25, 483-510.

Markman, G. D., Gianiodis, P. T., Phan, P. H., \& Balkin, D. B. (2005). Innovation speed: Transferring university technology to market. Research Policy, 34(7), 1058-1075.

Meurer, M., \& Bessen, J. (2014). The direct costs from NPE disputes. Cornell Law Rev, 99(2), 12-34.

Mowery, D. C. Nelson, R. R, Sampat, B. N., \& Ziedonis, A. A. (2004). Ivory tower and industrial innovation: University-industry technology before and after the Bayh-Dole Act in the United States. Stanford: Stanford University Press.

O'Shea, R. P., Allen, T. J., Chevalier, A., \& Roche, F. (2005). Entrepreneurial orientation, technology transfer and spinoff performance of US universities. Research Policy, 34(7), 9941009.

Ostrom, E. (2010). Beyond Markets and States: Polycentric Governance of Complex Economic Systems. American Economic Review, 100 (3): 641-72. 
Owen-Smith, J., \& Powell, W. W. (2003). The expanding role of university patenting in the life sciences: assessing the importance of experience and connectivity. Research Policy, 32(9), 1695-1711.

Owen-Smith, J., \& Powell, W. W. (2001). To patent or not: Faculty decisions and institutional success at technology transfer. The Journal of Technology Transfer, 26(1-2), 99114.

Pawson, R., Greenhalgh, T., Harvey, G., \& Walshe, K. (2005). Realist review-a new method of systematic review designed for complex policy interventions. Journal of health services research \& policy, 10(1_suppl), 21-34.

Payumo, J., Gang, Z., Pulumbarit, E., Jones, K., Maredia, K., \& Grimes, H. (2012). Managing intellectual property and technology commercialization: Comparison and analysis of practices, success stories and lessons learned from public research universities in developing Asia. Innovation, 14(4), 478-494.

Phan, P. H., \& Siegel, D. S. (2006). The effectiveness of university technology transfer. Foundations and Trends in Entrepreneurship, 2(2), 77-144.

Powers, J. B., \& McDougall, P. P. (2005). University start-up formation and technology licensing with firms that go public: a resource-based view of academic entrepreneurship. Journal of business venturing, 20(3), 291-311.

Rai, A. K. (2004). Open and collaborative research: A new model for biomedicine. Legal Studies Research Paper Series, Duke Law School, Research Paper No. 61, October 2004, 133.

Reid, R. H. (1997). Architects of the Web. John Wiley \& Sons, Inc.

Rhoten, D., \& Powell, W. W. (2007). The frontiers of intellectual property: Expanded protection versus new models of open science. Annu. Rev. Law Soc. Sci., 3, 345-373.

Salavisa, I., Sousa, C., \& Fontes, M. (2012). Topologies of innovation networks in knowledge-intensive sectors: Sectoral differences in the access to knowledge and complementary assets through formal and informal ties. Technovation, 32(6), 380-399

Sarasvathy, S. D. (2001). Causation and effectuation: Toward a theoretical shift from economic inevitability to entrepreneurial contingency. Academy of Management Review, 26(2), 243-263.

Shane, S. (2003). A General Theory of Entrepreneurship: The Individual-Opportunity Nexus. Northampton MA: Edward Elgar.

Siegel, D. S., \& Wright, M. (2015). Academic Entrepreneurship: Time for a Rethink? British Journal of Management, 26, 582-595.

Siegel, S. Waldman, D. A. Atwater, L. E., \& Link, A. N. (2003). Commercial knowledge transfers from universities to firms: improving the effectiveness of university-industry collaboration. The Journal of High Technology Management Research, 14(1), 111-133.

Siegel, S., Veugelers, R., \& Wright, M. (2007). Technology transfer offices and commercialization of university intellectual property: Performance and policy implications. Oxford Review of Economic Policy, 23(4), 640-660. 
Swamidass, P. M., \& Vulasa, V. (2009). Why university inventions rarely produce income? Bottlenecks in university technology transfer. Journal of Technology Transfer, 34(4), 343-63

Thursby, J. G., Jensen, R., \& Thursby, M. C. (2001). Objectives, characteristics and outcomes of university licensing: A survey of major US universities. The journal of Technology transfer, 26(1-2), 59-72.

Tranfield, D., Denyer, D., \& Smart, P. (2003). Towards a methodology for developing evidence-informed management knowledge by means of systematic review. British journal of management, 14(3), 207-222.

Uranga, G. M., Kerexeta, E. G., \& Campàs-Velasco, J. (2007). The dynamics of commercialization of scientific knowledge in biotechnology and nanotechnology. European Planning Studies, 15(9), 1199-1214.

Valdivia, W. D. (2013). University Start-ups: Critical for Improving Technology Transfer. Center for Technology Innovation at Brookings.

Valentin, F., \& Jensen, R. L. (2007). Effects on academia-industry collaboration of extending university property rights. The Journal of Technology Transfer, 32(3), 251-276.

Vega-Jurado, J. Gutierrez-Gracia, A. and Fernandez-de-Lucio, I. (2008) Analyzing the determinants of firm's absorptive capacity: beyond $\mathrm{R} \& \mathrm{D}, R \& D$ Management, 38 (4), 392405 .

Vohora, A., Wright, M., \& Lockett, A. (2004). Critical junctures in the development of university high-tech spinout companies. Research policy, 33(1), 147-175.

West, J. (2008). Commercializing open science: deep space communications as the lead market for Shannon Theory, 1960-73. Journal of Management Studies, 45(8), 1506-1532.

Westhorp, G., Walker, B., Rogers, P., Overbeeke, N., Ball, D., \& Brice, G. (2014).

Enhancing community accountability, empowerment and education outcomes in low and middle-income countries: A realist review. EPPI-Centre, Social Science Research Unit, Institute of Education, University of London.

White, A., \& Schmidt, K. (2005). Systematic literature reviews. Complementary therapies in medicine, 13(1), 54-60.

Wohlin, C. (2014). Guidelines for snowballing in systematic literature studies and a replication in software engineering. In Proceedings of the 18th international conference on evaluation and assessment in software engineering. ACM.

Wu, Y., Welch, E. W., \& Huang, W. L. (2015). Commercialization of university inventions: Individual and institutional factors affecting licensing of university patents. Technovation, 36, $12-25$.

Zahra, S. A., \& George, G. (2002). Absorptive capacity: A review, reconceptualization, and extension. Academy of Management Review, 27(2), 185-203.

Zahra, S. A., Van de Velde, E., \& Larraneta, B. (2007). Knowledge conversion capability and the performance of corporate and university spin-offs. Industrial and Corporate Change, 16(4), 569-608. 


\section{Compliance with Ethical Standards}

There are no conflicts of interest as this paper did not draw on any sources of funding, support for conference attendance and or the affiliation of authors with organisations that may have a vested interest in the issues discussed.

The data used are from previously published studies, thus considerations of informed consent and research involving human participants or animals are not relevant. 